\title{
Pakistan's fight against poliomyelitis: introducing innovative strategies to address challenges and attain the goal of eradication
}

\author{
N. Abid, ${ }^{7}$ O.U. Islam, ${ }^{1}$ A. Bosan, ${ }^{2}$ T. Iqbal, ${ }^{1}$ A. Darwish ${ }^{7}$ and K.M. Bile
}

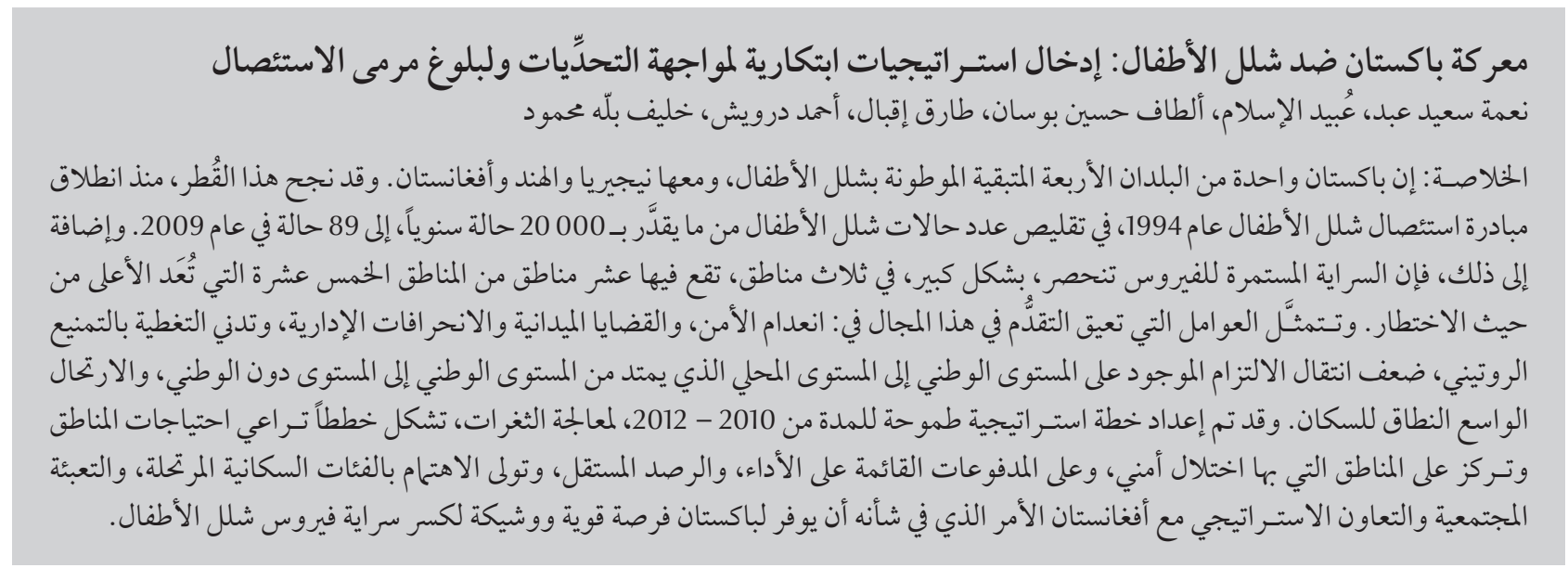

ABSTRACT Pakistan, with Nigeria, India and Afghanistan, is one of the four remaining polio endemic countries in the world. Since the start of polio eradication initiative in 1994, the country has succeeded in reducing the number of polio cases from an estimated 20,000 annually to 89 in 2009. Furthermore, persistent transmission is largely localized to three transmission zones in which ten of the fifteen highest risk areas are situated. Insecurity, operational issues, governance lapses, low routineimmunization coverage, inadequate trickle-down of the political commitment existing at the national level to sub-nationalleveland extensivepopulationmovement are the main barriers to the process. A robust strategicplan was developed for 2010-2012 encompassing district-specific plans and focused strategy on securitycompromised areas, performance-based payment, independent monitoring, attention to migratory populations, social mobilization, and strategic cooperation with Afghanistan. This will provide Pakistan a strong and imminent opportunity to interrupt polio virus circulation.

Lutte contre la poliomyélite au Pakistan : mise en place de stratégies innovantes pour traiter les problèmes et atteindre l'objectif d'éradication

RÉSUMÉ Avec le Nigéria, I'Inde et l'Afghanistan, le Pakistan est l'un des quatre derniers pays endémiques pour la poliomyélite dans le monde. Depuis le début de l'initiative pour l'éradication de cette maladie en 1994, le pays a réussi à ramener le nombre de cas annuels alors estimés à 20 000, à 89 cas en 2009. En outre, la transmission persiste essentiellement dans trois endroits, dans lesquels sont situées dix des quinze zones les plus à risque. Les principaux obstacles au processus d'éradication sont l'insécurité, les problèmes opérationnels, les défaillances de la gouvernance, la faible couverture de la vaccination systématique, l'insuffisante propagation de l'engagement politique du niveau national au niveau infranational et enfin, les larges mouvements de population. Grâce à un solide plan stratégique 2010-2012, englobant des plans de district, la stratégie d'éradication a été axée sur les zones mal sécurisées, les paiements fondés sur les résultats, un suivi indépendant, l'attention portée aux populations migrantes, la mobilisation sociale et la coopération stratégique avec l'Afghanistan. Ce plan offre au Pakistan une occasion forte et immédiate pour interrompre la transmission du poliovirus. 


\section{Introduction}

The World Health Assembly (WHA) through resolution WHA.41.28 adopted in 1988 called for the global eradication of poliomyelitis. The subsequent implementation of the Polio Eradication Initiative (PEI) strategies has resulted in over $99 \%$ reduction in the global annual incidence of poliomyelitis, from an estimated total of over 350000 cases prior to 1988 to only 1604 cases in 2009; and endemic circulation has been localized in 4 countries since 2006: Pakistan, Afghanistan, India and Nigeria [1].

Pakistan has achieved significant progress since the inception of PEI in the country in 1994. The number of confirmed cases has dropped from estimates exceeding 20000 per year in the early 1990s to 89 cases in 2009. The overall coverage of vaccination activities has been sustained at over $90 \%$ over the past 4 years, while inconsistency in the quality of supplementary immunization activities at subdistrict level has constituted a formidable challenge [2].

Furthermore, Pakistan and Afghanistan form a single epidemiologic bloc that allows the transmission of wild poliovirus across the border, primarily resulting from the large population movement between the 2 countriesthere is traditional seasonal migration and large numbers of mobile Afghan refugees [3].

An independent 2009 external assessment was conducted in Afghanistan, India, Nigeria and Pakistan, as advised by the WHO Executive Board, to evaluate the barriers to interrupting wild poliovirus transmission concluded that global poliomyelitis eradication is possible provided that the remaining problems, predominantlyattributable to insecurity and operationally surmountable challenges, are addressed through commitment and action [4]. Building on the lessons learned, a new strategic plan was developed for 2010-2012 by the Global Polio Eradication Initiative in consultation with local partners, and endorsed by the WHA in 2010 [3]. The plan aims at interrupting wild poliovirus transmission in at least 2 of the 4 remaining endemic countries by the end of 2011, and globally by the end of 2012

This paper is the result of a thorough review of data from: acute flaccid paralysis (AFP) surveillance, routinevaccinationandsupplementary immunization activities, reports of the Technical Advisory Group (national and international experts appointed by the WHO Regional Director for the Eastern Mediterranean Region) meetings, the 2009 independent evaluation and published technical papers relevant to polio eradication in Pakistan. It aims to assess the current status of the PEI in Pakistan, evaluate the outstanding challenges and identify the operational strategies necessary and sufficient to interrupt poliovirus transmission in Pakistan with a view to ensuring further progress towards eradication.

\section{Epidemiological update}

Despite the persistent transmission of wild poliovirus, currently $90 \%$ of the districts/towns/agencies have not reported any poliomyelitis cases over the first half of 2010. Since 1994, when the first national immunization days were conducted in Pakistan, the growing experience of the programme and its flexibility in adopting new tactics and technologies has resulted in a reduction of more than $99 \%$ in the annual number

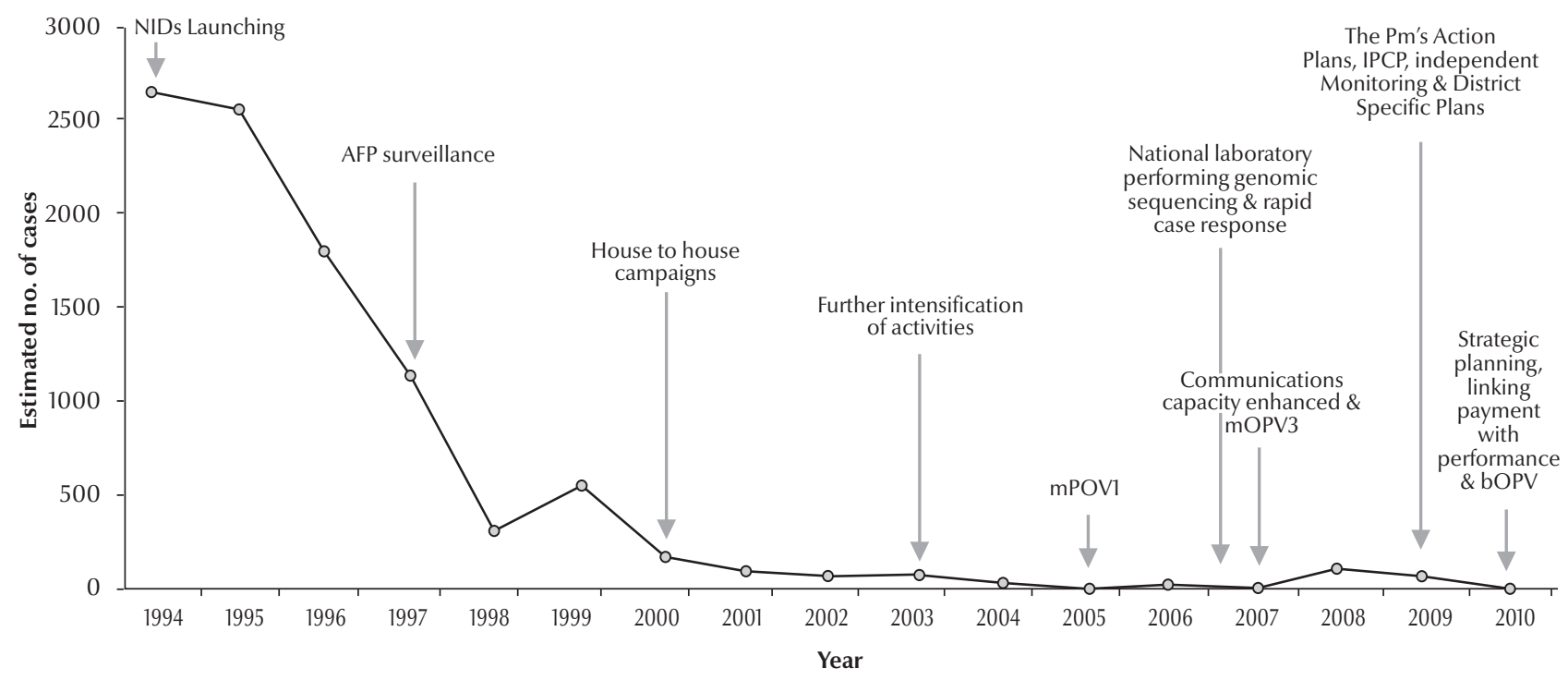

Figure 1 Poliomyelitis trends and significant milestones, Pakistan, 1994-2010 
of poliomyelitis cases in the span of 16 years (Figure 1).

Between 1 January and 18 July 2010, 30 wild poliovirus cases were reported from Pakistan compared to 23 in the corresponding period of 2009. Twenty (67\%) of the 30 emerged from the conflict-affected areas of Khyber Pakhtunkhwa (formerly known as North-West Frontier Province) and the Federally Administered Tribal Areas; 7 were from Baluchistan, 2 from Punjab and 1 from Sindh. Fourteen of the 30 were type 1 and 16 type 3; 9 (64\%) of the type 1 cases were reported from North Waziristan, Bajaur, Khyber and Mohmand agencies of the Federally Administered Tribal Areas. In the two most populous provinces, Punjab reported two cases while Sindh reported one case. In the Gilgit-Baltistan region of northern Pakistan no poliomyelitis cases have been detected for the past 12 years, while Pakistan-administered Kashmir has not reported any cases for 10 years. During 2010, three genetic clusters of type 1 and another of type 3 have been circulating, compared to four of type 1 and 3 of type 3 in 2009. While $47 \%$ of cases received fewer than four doses of oral poliomyelitis vaccine
(OPV), 55\% did not receive a routine OPV dose and $13 \%$ of the cases did not receive any poliomyelitis vaccination at all.

Table 1 shows the association between age and probability of contracting wild poliovirus infection in children with AFP between 2005 and 2009. Children aged 0-11 months, 12-23 months and 24-35 months had significantly greater risk of acquiring wild poliovirus infection relative to those 36 months and over. Surveillance data showed that the proportion of cases among the age cohort under 6 months was $4.6 \%$. Analyses also illustrate the significant inverse association between the number of OPV doses received by a child and the risk of acquiring the disease; there was no such association for sex-related differences.

Epidemiological data complemented by genetic analysis of isolated polioviruses substantiated the persistence of indigenous wild polio virus circulation in three discrete transmission zones, including three towns of Karachi (Baldia, Gadap and Gulshan-e-Iqbal); Peshawar in Khyber Pakhtunkhwa; the security-compromised Federally Administered Tribal Areas agencies of Khyber, Mohmand and Bajaur; and the three districts of Quetta, Pishin and Qilla Abdullah in north-western Balochistan (Figure 2). Moreover, the data revealed an additional five highest risk areas with repeated wild poliovirus infection. There has been confirmed annual cross-border transmission and sharing of wild poliovirus between $\mathrm{Pa}$ kistan and Afghanistan over the past five years.

\section{Status of PEI strategies in Pakistan}

\section{Routine immunization}

The Pakistan Social and Living Standards Measurement Survey conducted in 2008-09 revealed that diphtheriapertussis-tetanus vaccine (DPT3) coverage in children aged 12-23 months was $80 \%$ at the national level. However, based on the AFP surveillance data analysis of non-poliomyelitis AFP cases of the same age group in 2010, as of 5 July 2010, routine OPV3 coverage was $70 \%$ at the national level. The variations ranged from $80 \%$ in Punjab to $67 \%$ in Khyber Pakhtunkhwa, 63\% in Sindh, $38 \%$ in the Federally Administered Tribal Areas and 22\% in Balochistan,

\begin{tabular}{|c|c|c|c|c|}
\hline Variable & $\begin{array}{c}\text { All cases } \\
\text { (polio and non-polio) }\end{array}$ & $\begin{array}{l}\text { Pc } \\
\text { No. }\end{array}$ & $\%$ & Crude OR $(95 \% \mathrm{CI})$ \\
\hline \multicolumn{5}{|c|}{ Age of child (months) } \\
\hline $0-11$ & 2524 & 93 & 3.7 & $10.60(7.31-15.42)$ \\
\hline $12-23$ & 4446 & 117 & 2.6 & $7.49(5.24-10.74)$ \\
\hline 24-35 & 3821 & 51 & 1.3 & $3.75(2.46-5.71)$ \\
\hline 36 and above & 12516 & 45 & 0.4 & 1 \\
\hline \multicolumn{5}{|l|}{ Sex of child } \\
\hline Female & 9846 & 130 & 1.3 & $1.01(0.80-1.28)$ \\
\hline Male & 13461 & 176 & 1.3 & 1 \\
\hline \multicolumn{5}{|c|}{ All doses (routine and supplementary) } \\
\hline 0 dose & 534 & 56 & 10.5 & $17.06(12.22-23.76)$ \\
\hline $1-3$ doses & 1592 & 63 & 4.0 & $05.79(4.23-7.92)$ \\
\hline 4-6 doses & 1492 & 50 & 3.5 & $4.87(3.46-6.85)$ \\
\hline 7 and above & 19394 & 137 & 0.7 & 1 \\
\hline
\end{tabular}

$O R=$ odds ratio; $C l:=$ confidence interval. 

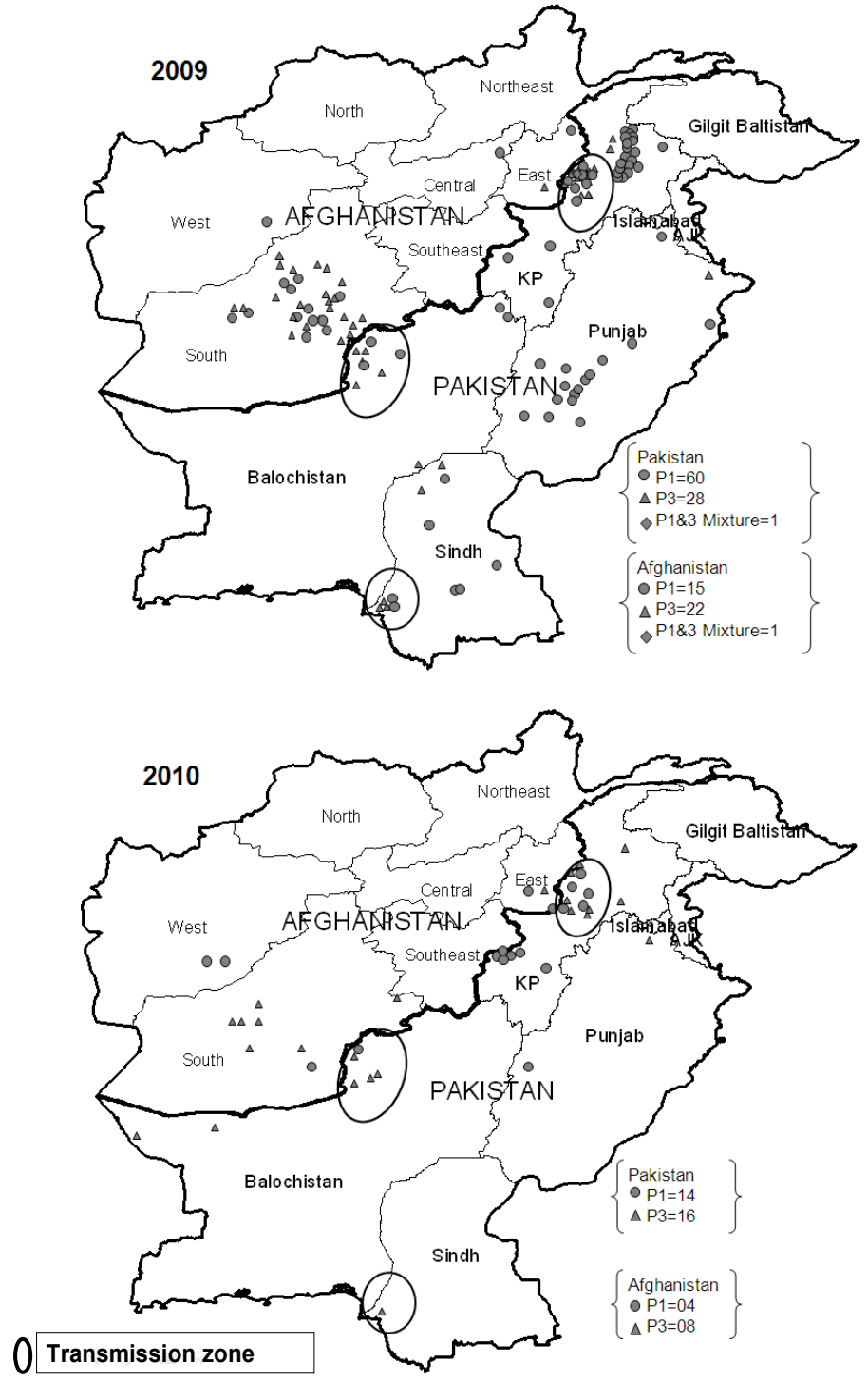

Figure 2 Poliomyelitis cases in Pakistan and Afghanistan in 2009 and 2010 as of 5 July 2010 illustrating shared transmission of zones

illustrating the inequity in routine immunization coverage in the country.

\section{Supplementary immunization activities}

Supplementary immunization strategies have been modified over the years in order to reach the maximum number of children. The provision of OPV through fixed points during national immunization days, pursued from 1994 to 1999 (Figure 1) was replaced by a house-to-house strategy from 2000 onwards. With the localization of wild poliovirus circulation, subnational immunization days were introduced in 2001 to specifically target children in high risk areas. For risk assessment purposes, districts, towns and agencies were categorized into low, medium, high or highest risk areas, relative to surveillance data analysis including poliomyelitis epidemiology and the performance quality of district health teams during the supplementary immunization activities. High risk and highest risk districts were targeted with more supplementary immunization activities, intensified technical assistance and closer oversight (Table 2). The supplementary immunization activities' microplans (operational plans prepared before each campaign at the sub-union council level) are regularly reviewed and updated. In 2009, a decision was taken to regard finger-marking of the distal part and the nail of the left little finger using an indelible marker as the sole proof for child vaccination validated by a standardized process of independent monitoring. A total of 38 million doses of OPV are provided during each national immunization day round, and their timely dispatch and distribution is an essential prerequisite for ensuring coverage to more than 30 million under five-year-old children.

\section{AFP surveillance system}

The AFP surveillance system was launched in 1997, and the non poliomyelitis AFP rate per 100000 children below 15 years of age increased gradually from 0.8 per 100000 in 1997 to 2.0 per 100000 in 2001. It was 6.13 in 2009 (the target is more than 2 per 100000 children under 15 years). Similarly, AFP cases with adequate stool specimens increased from $31 \%$ in 1997 to $80 \%$ in 2001, while over the past three years the rate has remained at $90 \%$ or more. The supplemental surveillance activities being implemented included the collection of samples from at least three contacts if adequate specimens could not be obtained from an AFP case. This strategy was initiated in 2004 and has reached a completeness rate of $92 \%$ in 2010, contributing to the detection of 31 of 354 reported poliomyelitis cases. Another supplemental surveillance activity introduced in 2009 is environmental monitoring. Samples are collected from Karachi and Lahore, and recently also from Peshawar, Quetta and Rawalpindi, demonstrating results consistent with AFP surveillance, except for two genetically distinct chains of type 1 poliovirus, 1 each in Karachi and Lahore, that were detected through environmental sampling. The National Institute of Health in Islamabad, which houses the regional reference laboratory for Pakistan and Afghanistan (which 


\begin{tabular}{|c|c|c|c|c|c|}
\hline $\begin{array}{l}\text { Risk categorization } \\
\text { of districts/towns/ } \\
\text { agencies }\end{array}$ & Selection criteria & $\begin{array}{l}\text { No. of districts/ } \\
\text { towns/agencies } \\
\text { in each group }\end{array}$ & $\begin{array}{l}\text { No. of } \\
\text { NIDs }\end{array}$ & $\begin{array}{l}\text { No. of } \\
\text { SNIDs }\end{array}$ & $\begin{array}{c}\text { Additional } \\
\text { technical and } \\
\text { oversight support }\end{array}$ \\
\hline Low risk & Very low probability of importation & 59 & 4 & - & + \\
\hline Medium risk & $\begin{array}{l}\text { High probability of importation from high } \\
\text { risk districts }\end{array}$ & 49 & 4 & 2 & ++ \\
\hline High risk & $\begin{array}{l}\text { Part of endemic transmission zones or } \\
\text { geographically close to the highest risk } \\
\text { districts or high population density and } \\
\text { frequent population movement with active } \\
\text { transmission zones }\end{array}$ & 13 & 4 & 4 & +++ \\
\hline Highest risk & $\begin{array}{l}\text { Persistent transmission districts/ towns/ } \\
\text { agencies (10) and repeatedly infected (5) }\end{array}$ & 15 & 4 & 4 & ++++ \\
\hline
\end{tabular}

NIDs = national immunization days; SNIDs = supplementary national immunization days .

performs genomic sequencing), tested stool samples for polioviruses and reported diagnostic confirmation within 14 days of receipt for $98 \%$ of specimens in 2009 (target $\geq 80 \%$ ).

\section{Operational strategies}

\section{Strategic plan for 2010-12}

The national Inter-Provincial Committee on Polio (IPCP), chaired by the Federal Minister for Health and including all provincial ministers for health, approved a three-year plan to intensify operations with a major emphasis on enhancing ownership and accountability. The committee approved the globally endorsed process indicators that set specific benchmarks for Pakistan, where successful PEI implementation in Karachi in 2010 would require that less than $10 \%$ of the target children in each town are missed during every round in at least four supplemental immunizations. For the persistent transmission areas in Balochistan, Khyber Pakhtunkhwa and the Federally Administered Tribal Areas, the proportion of missed target children was required to be lower than $15 \%$ in at least eight supplemental immunizations carried out during 2010.

\section{District-specific plans}

All districts in Pakistan have PEIspecific plans; however, a more targeted approach is being adopted for the 15 highest risk areas, representing districts, agencies and towns promoting specific operations relevant to routine immunization, supplemental immunization activities, surveillance and communications. The plans were designed to address the challenges encountered in each highest risk area through targeted and specificlocally appropriate interventions. The impeded access to the target population has been primarily related to governance lapses or security-related challenges in the programme catchment areas. To improve the PEI performance in these areas, plans include additional supplemental immunization rounds to boost immunity; enhancing technical oversight to improve the quality of operations; ensuring that monitoring activities cover all the union councils (the lowest administrative units in a district) to achieve uniform quality; and convening monthly review meetings at provincial level and quarterly meetings at federal level to assess the progress in the fight against poliomyelitis.

The strategy for the Federally Administered Tribal Areas focuses on improving access of children to vaccination, considering the complex security situation due to active conflict. This situation meant that children were deprived of access to vaccination and this has resulted in a higher number of wild poliovirus type 1 cases than other provinces of Pakistan and all other endemic countries collectively during 2010. The number of inaccessible target children in the Federally Administered Tribal Areas has consequently increased, from about 200000 (18\% of the operational target) during most supplementary immunization activities in 2009 to more than 300000 ( $27 \%$ of the target children) in 2010. To address this growing inaccessibility and guide the advocacy, negotiation and intervention tactics that ensure the safety of vaccination teams and facilitate access to the target child population, the region was categorized into three zones.

- Army-held zones where access is permitted with security being volatile: all efforts are to be made to achieve the best possible coverage through improved governance and tightened supervision.

- Army-held areas where access is denied owing to safety concerns: flexible plans are being prepared, including advocacy with army leaders, secured logistics and funds that allow swift vaccination drives including shortinterval additional dose strategy campaigns during windows of opportunity created through formal and informal negotiations. These efforts are coordinated with the government and local community and jirga (tribal assembly) leaders.

- Areas where the government control is particularly weak and access highly 
problematic: local communityleaders were negotiated with and organized to carry out short-interval additional dose strategy immunization in liaison with local authorities and advocating PEI neutrality to gain access and protection for vaccinators.

The short-interval additional dose strategy was successful in Swat, where a poliomyelitis outbreak at the end of two years of continuous inaccessibility was effectively controlled with five rounds of immunization rapidly conducted over four months.

In Karachi's highest risk towns, the strategy focused on: enhancing the active engagement of the health department leadership, with political parties' commitment to directly interact and influence town health management and catalyse community social mobilization among the highest risk and underserved populations; ensuring that all the vaccination teams were selected from the local community in order to address prevailing cultural sensitivities; building operational partnership with nongovernmental organizations and the private sector to supplement the overstretched public sector services. The strategy allows local partners to participate in the delivery of immunization services and facilitate social mobilization to improve performance of supplementary immunization activities.

The district level plan for the highest risk areas of Balochistan demands direct oversight by the deputy commissioners (the chief executives at district level), with special emphasis on engaging the leadership of the paramedical staff association, which has constituted the major challenge to PEI operations' governance in this province. Focused advocacy is being targeted to communities and the religious leadership to overcome the few existing pockets of chronic refusals to vaccinate against poliomyelitis resulting from baseless rumours concerning vaccine safety.

These plans are monitored throughprovincial reviews on a monthly basis and federally every quarter to ensure progress in the implementation quality (consistently over 90\%), particularly in Karachi and Balochistan. Modest progress was also attained in Khyber Pakhtunkhwa, but the situation in the Federally Administered Tribal Areas worsened in 2010 due to the deteriorating security situation.

\section{Independent performance monitoring}

The outcome of the supplementary immunization activities is assessed regularly by independent monitors verifying the vaccination status of children through finger-marking. Monitors, preferably females and familiar with the local language(s), are recruited from universities, colleges, nongovernmental organizations and the education department. All the Union Councils from high and highest risk areas are assessed, while $50 \%-70 \%$ of medium and $25 \%$ of low risk districts are monitored, with special attention to areas having higher likelihood of underperformance. Monitoring results showed finger-marking coverage rates of at least $90 \%$ in all provinces and regions except the Federally Administered Tribal Areas where access was seriously compromised (Figure 3).

\section{Performance based payment}

The IPCP decided to release the final payment of the operational budget conditional on monitors' verification of at least $90 \%$ finger-marking coverage in a district. The proportion of districts achieving at least 90\% finger-marking confirmed coverage, increased from $61 \%$ in January 2010 to $82 \%$ in May

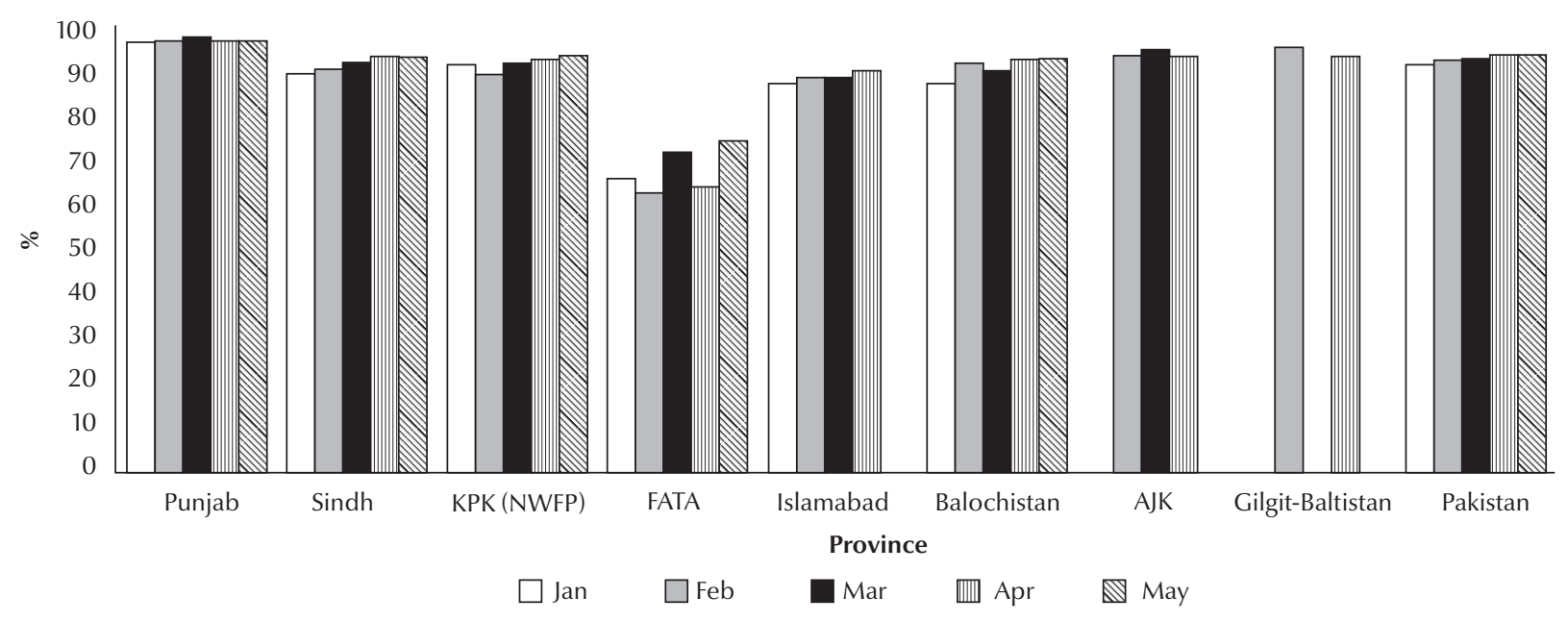

Figure 3 Finger-marking coverage through independent monitoring in children under 5 years, Pakistan, January-May 2010 [adjusted coverage $=$ assessed coverage $\times\left(1-\mathrm{P}^{\circ}\right) ; \mathrm{P}^{\circ}=$ proportion of children inaccessible due to insecurity]. KPK = Khyber Pakhtunkhwa; FATA = Federally Ddministered Tribal Areas; AJK = Azad Jammu and Kashmir 
2010, demonstrating the positive impact of this managerial decision.

\section{Migratory populations}

Migratory groups, including nomads, agriculture, construction and other seasonal workers, internally displaced persons (IDPs) and Afghan refugees, often pose the risk of sustaining poliovirus transmission between regions and districts owing to their high mobility and settlement in underserved geographi$\mathrm{cal}$ areas. The eradication initiative has recently revamped a strategy to effectively cover these populations through specific microplans and mechanisms to track their movement and enhance their access to vaccination services. Special vaccination teams are raised to target these groups along known transit routes or while residing in temporary stay locations both during and outside scheduled supplementary immunization activities with close monitoring of performance. Consequent to this strategy, the June 2010 special vaccination campaign reached approximately 250000 children in 16 Union Councils of Sindh and Balochistan having a high concentration of migratory populations.

\section{Enhancing communication and social mobilization}

As integral components of the PEI, communication and social mobilization were intensified in 53 intervention areas including the 15 highest risk areas. To promote these initiatives, innovative partnerships were developed through the Prime Minister's Action Plan launced in early 2009 to enhance intersectoral collaboration between the public and private sectors and with the involvement of the civil society.

A major component of the communication strategy included the engagement of religious leaders. Key religious scholars belonging to different schools of thought have reiterated their support for PEI by delivering 17 religious edicts or fatwas in support of poliomyelitis eradication and routine immunization, leading to a considerable reduction in refusals to vaccinate against poliomyelitis to less than $0.5 \%$. Aninterreligious council on health with representation from Islamic, Christian, Sikh, Parsi and Hindu groups supports the immunization programme with a stipulated plan for enhancing public awareness through activities at the district level.

Knowledge, attitudes and practice studies have shown that parents' awareness of poliomyelitis as an important health issue increased from $83.9 \%$ in 2008 to $91.7 \%$ in 2010 [5]. Moreover, there were significantly more media events that were supportive of the PEI (2500 of 2552) than those raising concern, e.g by questioning the efficacy or safety of the vaccine.

\section{Government ownership}

Poliomyelitis eradication has always been at the top of the health agenda of successive Pakistani governments. To promote programme ownership and commitment, advocacy efforts were launched with elected representatives resulting in the formation of a caucus of parliamentarians to support poliomyelitis eradication. The President and the Prime Minister of Pakistan launched the national immunization days in 2009 and 2010, while the IPCP has met three times since its inception in 2009 and provided impetus to the government's resolve on PEI at the sub-national as well as the national level. At the district level, the district commissioner chairs the district polio eradication committee before each supplementary immunization to mobilize support from government line departments and other partners in the district. In the supplementary immunization activities conducted during May 2010, district polio eradication committee meetings were held before the campaign chaired by high level managers in $98 \%$ of the districts, compared to $76 \%$ in the January round of the same year.

\section{Cross-border collaboration with Afghanistan}

The first cross-border immunization post was established in 2002 at Khyber Pass (Torkham) and subsequently extended to 10 other crossing points along the 2430 kilometre border with Afghanistan. The fact that all genetic lineages of wild poliovirus circulating in both countries in 2010 are related to each other, reflecting a shared transmission between the two countries due to extensive population movement, reinforces the need for closer cross-border coordination and collaboration. During 2008 and 2009, two intercountry meetings were held with senior health officials of the two countries for PEI joint planning and coordination, leading to the synchronization of three of the five scheduled supplementary immunization activities in 2010. In 2009, approximately two million border-crossing eligible children were vaccinated by the permanent cross-border vaccination teams of the two countries.

\section{Discussion}

The 22-year old PEI has remained at the top of the global public health agenda with a remarkable restriction of wild poliovirus circulation to localized areas of the four remaining poliomyelitisendemic countries compared with 125 in 1988 [3]. The plausibility of poliomyelitis eradication was further reinforced by the 2009 independent evaluation report, asserting the attainability of this goal [4]. Pakistan has reported the highest number of poliomyelitis cases in 2010 relative to other endemic countries. Although there are major operational challenges, the country possesses several opportunities to make a major breakthrough in interrupting wild poliovirus circulation. This is corroborated by the fact that persistent transmission is restricted to three zones of central Khyber Pakhtunkhwa and the Federally Administered Tribal Areas; 
Quetta, Pishin and Qilla Abdullah of Balochistan; and the Karachi zone. Accordingly, the majority $(20 / 30)$ of the cases detected up to 18 July 2010 were from these transmission zones, while most of the viruses detected elsewhere were genetically related to the same. It is also important to note that 10 of the 15 highest risk areas fall in the wild poliovirus transmission zones. Likewise, most of the security-compromised areas are in or adjacent to the Khyber Pakhtunkhwa-Federally Administered Tribal Areas transmission zone.

Quite significantly, the law-andorder challenges are not restricted to the areas affected by the crisis in the Federally Administered Tribal Areas, as they occasionally hamper programme operations in Balochistan, Karachi and northern Sindh. These realities underline the magnitude of the prevailing challenge, while at the same time accentuate the imperative to develop dynamic specific plans and adjust the PEI programme implementation, authenticating the validity of the risk categorization approach. However, the predominant challenge facing the highest risk areas of Karachi and Balochistan are the inadequate management and weak accountability observed, especially at district level, though recently introduced efforts and strategies for enforcing accountability and closer oversight led by the health departments have produced tangible improvements in the programme implementation [6].

Genetic sequencing data showed that the wild poliovirus had spread from these transmission zones to many formerly poliomyelitis-free areas such as central Punjab, which suffered an outbreak in 2008 in which complacency, reduced frequency of supplementary immunization activities, deterioration of routine immunization, high population movement and an influx of internally displaced populations from poliomyelitisendemic, insecure areas played a major role in re-establishing wild poliovirus circulation $[7,8]$.
Epidemiological data have revealed a significant statistical association between the age of the child and the probability of contracting poliomyelitis: the younger the child, the higher the risk of contracting the disease, with the exception of the low incidence in infants under six months of age, attributed to low exposure to the risk of infection and/or to passive immunity from maternal antibodies [9]. It is, however, critical to reach out to this youngest age cohort during supplementary immunization activities in order to reduce the pool of susceptibles and overcome the habit observed predominantly in rural areas, where access to newborn infants is impeded as they are concealed from outsiders.

Moreover, the study corroborated that children receiving seven doses or more were at significantly lower risk of acquiring the disease compared to those receiving six or fewer doses. The latter finding is supported by other studies revealing that the immunogenicity of OPV is lower in infants in developing countries because of a higher prevalence of competing enteroviruses, recent diarrhoeal episodes and malnutrition relative to infants in industrialized countries [9-11]. This substantiates the need to ensure access of every eligible child to all opportunities for routine and supplementary vaccinations.

Improving routine immunization is one of the cornerstones of poliomyelitis eradication: combined efforts exerted at the district, provincial and federal tiers of government should address current programmatic weaknesses - correcting the health workforce maldistribution and ineffective managerial and logistic arrangements that impede access to vaccination against poliomyelitis and other vaccine-preventable diseases. Concerted efforts are therefore required by the district health management team to improve district immunization operational plans, and the equitable distribution of vaccinators with the active involvement of Lady Health Workers in immunization service delivery, while benefiting from the strong communication and social mobilization skills developed over the years during supplementary immunization activities. Given the current low level of routine immunization coverage, Pakistan has to conduct at least 4 national immunization days a year, although the latter would not be able to offset or substitute the significant role of routine immunization in poliomyelitis eradication [12].

A uniformly high performance in supplementary immunization activities throughout the country at all levels of government is central to the efforts aimed at interrupting wild poliovirus circulation, complemented by further intensification of programme operations in the transmission zones. Despite the observed overall high coverage rates, there are still supplementary immunization-related governance lapses such as inefficiency or misuse of resources in some districts and subdistricts because of deficient vaccination teams, poor training quality, misreporting and delayed or denied payments to vaccination teams in addition to the significant number of unreached children in security-compromised areas [4]. To overcome these challenges, district health teams operating in high risk zones have to effectively pursue the area-specific plans, the latter being crucial to the success of poliomyelitis eradication. The recent government resolve of validating the coverage data through finger-marking, reliably generated by independent monitors, and the linking of payment of campaign remunerations with this performance, has proved operationally effective. The regular appraisal meetings held by the provincial chief secretaries and deputy commissioners are powerful forums for tracking progress, rectifying governance faults and providing oversight to the entire implementation process $[13,14]$. Considering the process indicators of the global strategic plan, the course of implementation in Pakistan is confidently on track, though 
the security-compromised areas fall significantly short of expectations and merit stronger interventions.

Since 2001, AFP surveillance indicators in Pakistan have been meeting the WHO targets, and the strategy has successfully guided the PEI operations that have led to a dramatic decrease in poliomyelitis incidence, providing the opportunity in future to spearhead the establishment of an integrated disease surveillance system in Pakistan [15]. However, an AFP surveillance weakness was recently identified in the system when some "long-chain" ("orphan") polioviruses were detected through genetic mapping of wild polioviruses [16]. This suggests the need for enhanced surveillance capacity as well as improving vaccination coverage among migratory and underserved populations.

The decision to set specific plans for the 15 highest risk areas was an effective strategic operation as these areas produced $60 \%$ of the confirmed poliomyelitis cases in 2010, while the wild poliovirus circulation elsewhere was also closely linked with the ongoing circulation in these highest risk areas. The recent improvement in programme performance in these areas validates the efficacy of this approach with the exception of the crisis-affected Federally Administered Tribal Areas [17].

The first building blocks of the Federally Administered Tribal Areas strategy emphasize programme neutrality and focus on child survival, regardless of which group or conflict rivals the children come from. This substantiates the legitimate prioritization of PEI and its neutrality, and hence the validity of the protection demanded for vaccination teams: in areas of active conflict it is important to ask the government authority and the army as well as the local community leaders to provide protection and safe passage to the teams. The strategy engages local opinion leaders as focal persons; mobilizes support and acceptance from the tribal assemblies or jirga with a constant search for windows of opportunity to conduct short-interval additional dose strategy campaigns. Poliomyelitis vaccinations need also to be considered as "add on" strategies to ongoing health and other community interventions to secure better access to vaccination. Moreover, the establishment of vaccination posts on the exit and entry routes of the crisis-affected areas and efforts to maintain high coverage in all accessible areas within the Federally Administered Tribal Areas and the adjacent areas of Khyber Pakhtunkhwa are critical components of the strategy, aiming to create a barrier that buffers virus transmission. This vision could be further consolidated by expanding the social health assets by promoting a comprehensive primary health care package in the area. Interventions that were operationally consistent with the current Federally Administered Tribal Areas strategy have led to the interruption of wild poliovirus transmission in other conflict-affected areas such as in Cambodia, Colombia, Somalia, Sri Lanka and southern Sudan $[2,18]$.

Evidence-based and innovative communication strategies will remain critical to the final push of poliomyelitis eradication [19]. The establishment of the National Polio Control Cell (which provides information to parents of children who have missed vaccination via a toll-free number) through a coalition of public and private television channels, communitybased approaches in the Federally Administered Tribal Areas, and advocacy briefing endeavours for political leaders, religious scholars and parliamentarians have broadened the scope of the communication strategy and raised awareness among the public, attracting a greater number of stakeholders in support of the programme. Although numerically insignificant, the potential impact of negative media could be substantial, mandating the proactive design of preventive communication strategies to diffuse the effect of misinformation.

The extensive cross-border population movement between Afghanistan and Pakistan necessitates the coordination of PEI interventions and the mobilization of the required international support for interrupting wild poliovirus circulation in this region.

The strategic plan for 2010-12 has laid down an operational course of action to which the national and health sector political leadership has subscribed, mandating the convening of regular IPCP meetings to steer poliomyelitis eradication efforts; enhancing ownership and accountability; improving quality of implementation; reinforcing specific plans for the highest risk areas; recruiting vaccination teams familiar with local languages; applying appropriate communication strategies; and rationalizing resource use. In the Federally Administered Tribal Areas the strategic package needs to be pursued by closely liaising with government institutions and influential community partners, while flagging and maintaining programme neutrality and prioritization. Targeting the high risk, underserved, migrant populations while travelling and at temporary stay locations has also proved to be a sound strategy.

Given the coherent political commitment currently evolving in all tiers of government, the localization of wild poliovirus circulation, the availability of potent vaccines, improving leadership commitment at all levels, the imperative of effective and high quality supplementary immunization activities, impeccable and highly sensitive surveillance, the extended support of development partners and the district- and regionalspecific operational plans, Pakistan has every opportunity to interrupt endemic wild poliovirus circulation, attain the globally set milestones and lead the nation to the goal of poliomyelitis eradication in the near future. 


\section{References}

1. Progress toward interruption of wild poliovirus transmissionworldwide, 2009. Morbidity and Mortality Weekly Record, 2010, 59(18):545-550.

2. Poliomyelitis eradication in the Eastern Mediterranean Region: progress report 2007-2008. Cairo, World Health Organization Regional Office for the Eastern Mediterranean, 2009 (WHOEM/POL/380/E; at http://www.emro.who.int/polio/pdf/ progressreport_07_08en.pdf, accessed 27 July 2010).

3. GlobalPolioEradicationInitiative:strategicplan2010-2012.Geneva, World Health Organization, 2010 (at http://www.polioeradication.org/content/publications/GPEI.StrategicPlan.2010-2012. ENG.May.2010.pdf, accessed 27 July 2010).

4. Global Polio Eradication Initiative. Independent evaluation of major barriers to interrupting poliovirus transmission. Geneva, World Health organization, 2009 [Website] (http://www polioeradication.org/content/general/Polio_Evaluation_ Report.asp, accessed 5 July 2010).

5. Household polio KAP tracking study, Phase-VI, December 2009 Islamabad, SoSEC consulting Services, 2009.

6. Report on the meeting of the Technical Advisory Group on poliomyelitis eradication in Afghanistan and Pakistan, Islamabad, Pakistan, 11-12 May 2010. Cairo, World Health Organization Regional Office for the Eastern Mediterranean, 2010 (WHO$\mathrm{EM} / \mathrm{POL} / 386 / \mathrm{E})$.

7. Report on the meeting of the Technical Advisory Group on poliomyelitis eradication in Afghanistan and Pakistan, Cairo, Egypt, 3-4 February 2008. Cairo, World Health Organization Regional Office for the Eastern Mediterranean, 2008 (WHO-EM/ $\mathrm{POL} / 366 / \mathrm{E})$.

8. Conclusions and recommendations of the advisory committee on poliomyelitis eradication, November 2009. Weekly Epidemiological Record, 2010, 85(1-2):1-7.

9. Patriarca PA, Wright PF, John TJ. Factors affecting the immunogenicity of oral polio vaccine in developing countries: review. Review of Infectious Diseases, 1991, 13:926-939.
10. Posey DL et al. The effect of diarrhea on oral polio vaccine failure in Brazil. Journal of Infectious Diseases, 1997, 175(Suppl. 1):S258-263.

11. Swartz TA et al. Routine administration of oral polio vaccine in a subtropical area: factors possibly affecting sero-conversion rates. Journal of Hygiene,1972,70:719-726.

12. Pakistan demographic and health survey 2006-2007. Islamabad, Pakistan, National Institute of Population Studies, 2008.

13. Report on an emergency technical consultation on polio eradication in Pakistan. Karachi, Pakistan, June, 2008. Cairo, Eastern Mediterranean Regional Office, World Health Organization, 2008 (WHO-EM/POL/371/E).

14. Lowther SA et al. Characteristics of districts in Pakistan with persistent transmission of wild poliovirus 2000-2001. Eastern Mediterranean Health Journal, 2004, 10(4-5):582-590.

15. Pakistan's public health surveillance system: a call to action. Washington DC, World Bank, 2005 (Report No.329363-PK).

16. Progress toward poliomyelitis eradication-Afghanistan and Pakistan, 2009. Morbidity and Mortality Weekly Report, 2010, 59(9):268-273.

17. Global Polio Eradication Initiative. Monthly situation report, May 2010. Geneva, World Health Organization, 2010 [Website] (http://www.polioeradication.org/content/general/poliositrepMay2010.asp, accessed 10 July 2010).

18. Tangermann RH. Eradication of poliomyelitis in countries affected by conflict. Bulletin of the World Health Organization, 2000, 78(3):330-338.

19. Obergon R et al. Achieving polio eradication: a review of health communication evidence and lessons learned in India and Pakistan. Bulletin of the World Health Organization, 2009, 87:624-630. 